Check for updates

Cite this: Chem. Sci., 2019, 10, 11006

๑ All publication charges for this article have been paid for by the Royal Society of Chemistry

Received 9th October 2019

Accepted 29th October 2019

DOI: $10.1039 / c 9 s c 05087 f$

rsc.li/chemical-science

\section{Facile synthesis of fluorescent hetero[8]circulene analogues with tunable solubilities and optical properties $\dagger$}

\author{
Yusuke Matsuo, Fengkun Chen, Koki Kise, Takayuki Tanaka (D) * and Atsuhiro Osuka
}

Hetero[8]circulenes are an interesting class of polycyclic heteroaromatic molecules having rigid and planar structures, which are promising in light of their potential applications for OLEDs, OFETs and so forth. Although their synthetic methods have been developed in some specific cases, a facile synthetic protocol of novel hetero[8]circulenes with tunable properties is highly desirable. We herein report the unexpected formation of methoxy-substituted quasi-aza[8]circulene and its conversion into unprecedented triazaoxa[8]circulene. The structures and optical properties were comparatively studied. Remarkably, triazaoxa[8]circulene is highly soluble in THF, acetone and DMSO mainly because of effective hydrogen-bonding of the $\mathrm{NH}$ moieties to these solvents. Their highly soluble nature in various solvents enabled us to study the solvent effects of these molecules. In particular, triazaoxa[8]circulene displays a high fluorescence quantum yield of 0.72 in DMSO. Furthermore, enantiomeric separation of highly distorted quasi-aza[8]circulene was successfully achieved by chiral HPLC. Thus, these novel hetero[8]circulene derivatives are practically useful fluorescent nanographene-like molecules with intriguing optical properties.

\section{Introduction}

Hetero[8]circulenes belong to a class of polycyclic heteroaromatic molecules (PHAs) possessing eight alternately arranged condensed arenes and/or heteroles that surround a central eight-membered ring. ${ }^{1-3}$ Unlike the parent all-benzene analogue (i.e. [8]circulene) adopting a saddle-shaped conformation, ${ }^{4}$ most of the hetero[8]circulenes take planar structures and have attracted considerable attention as promising materials for organic electronics. ${ }^{5-10}$ One of the old examples is tetraoxa[8]circulene 1 reported by Erdtman et al. in 1968, ${ }^{5}$ which was synthesized by acid-catalyzed condensation of $\alpha$-naphthoquinone although its formation was only identified by mass analysis due to its extremely poor solubility (Chart 1). Several tetraoxa[8]circulene derivatives were reported later on, ${ }^{6}$ but it was not until 2013 that hetero[8]circulenes including units other than furan units were prepared. Azatrioxa[8]circulene 2 and diazadioxa[8]circulene 3 were synthesized by Pittelkow et al. by using hydroxy-substituted carbazole precursors under acidic conditions. ${ }^{7}$ Recently, we reported the first synthesis of tetraaza

Department of Chemistry, Graduate School of Science, Kyoto University, Sakyo-ku, Kyoto 606-8502, Japan.E-mail: taka@kuchem.kyoto-u.ac.jp

$\dagger$ Electronic supplementary information (ESI) available: Experimental and computational details and X-ray crystallographic data for 12c, 13d, 14, 12a-Bu, 12c-Bu and 14-Bu are available. CCDC 1953592-1953597. For ESI and crystallographic data in CIF or other electronic format see DOI: 10.1039/c9sc05087f [8]circulene 5 by a fold-in type oxidative fusion reaction of orthophenylene-bridged cyclic tetrapyrrole $4 .^{8 a}$ From octabromotetraphenylene $\mathbf{6}$, Wong et al. synthesized tetrathia- and tetraselena[8]circulenes $\mathbf{7}$ and $\mathbf{8}$ by Li-mediated nucleophilic reactions followed by thermal annealing. ${ }^{9 a}$ Miyake and Shinokubo utilized tetraboryltetrathienylene $\mathbf{9}$ as a precursor of tetrathia[8] circulenes $10{ }^{10}$ Interestingly, multiply alkylated tetrathia[8]circulenes form aggregates in $\mathrm{CDCl}_{3}$ depending on the number of peripheral substituents. ${ }^{10 b}$ Despite this progress, all these reactions required specific synthetic precursors or harsh reaction conditions, precluding the fine property tunability of [8] circulenes. A facile synthetic approach toward unprecedented hetero[8]circulenes is thus highly desirable.

Recently, we reported the synthesis of triaza-quasi-[8]circulene 12a, ${ }^{11}$ which lacks one heterole moiety from the hetero[8] circulene structure. ${ }^{12}$ Due to the structural constraint, 12a takes on a non-planar geometry. Interestingly, under milder conditions, triaza[7]helicene 13a was exclusively obtained from the identical precursor 11a. Dimethyl-substituted triaza[7]helicene 13b was then synthesized to estimate a helicene racemization activation free energy of $23.8 \mathrm{kcal} \mathrm{mol}^{-1}$ (at $298.15 \mathrm{~K}$ ). On the other hand, the racemization rate of 12a was computed to be too fast for experimental determination.

Herein, we report an unexpected formation of dimethoxysubstituted triaza-quasi-[8]circulene 12c and its conversion to the hitherto unknown triazaoxa[8]circulene 14. The planar and non-substituted triazaoxa[8]circulene $\mathbf{1 4}$ was surprisingly well soluble in polar solvents such as THF and acetone. The solvent- 
(a) Synthesis of tetraoxa[8]circulene (Erdtman et al. 1968)
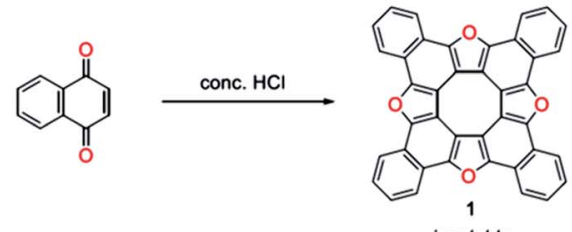

insoluble (c) Synthesis of tetraaza[8]circulene (Tanaka, Osuka et al. 2015)

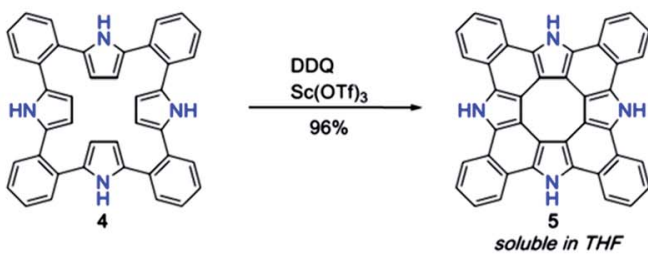

(b) Synthesis of azatrioxa- and diazadioxa[8]circulenes (Pittelkow et al. 2013 )

(d) Synthesis of tetrathia- and tetraselena[8]circulenes from tetraphenylene derivative (Wong et al. 2015)
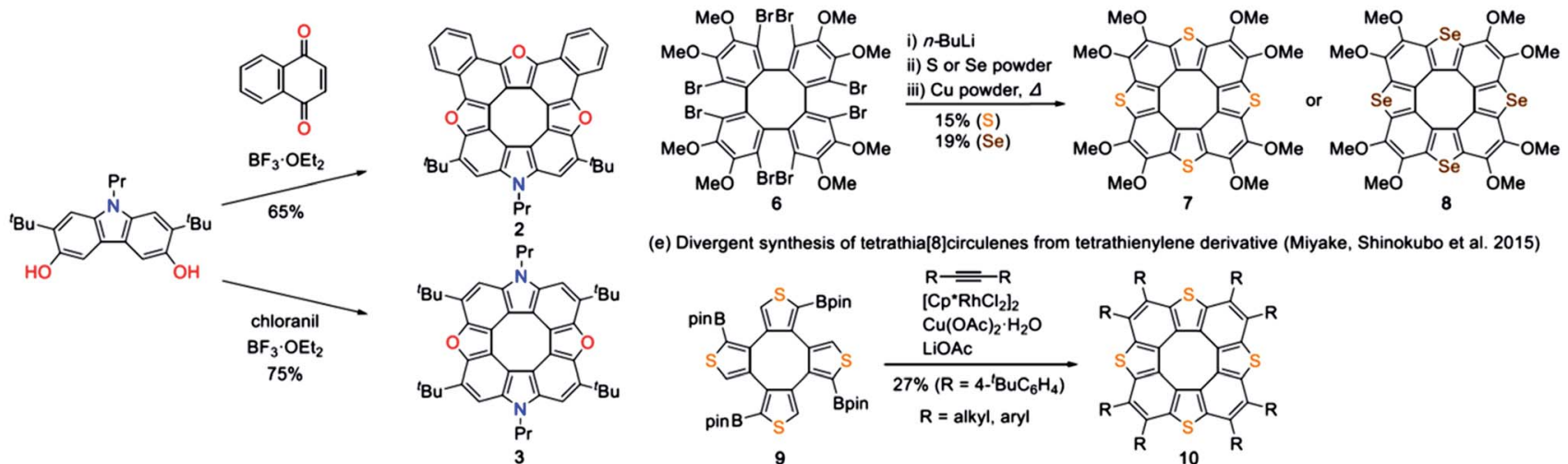

(e) Divergent synthesis of tetrathia[8]circulenes from tetrathienylene derivative (Miyake, Shinokubo et al. 2015)

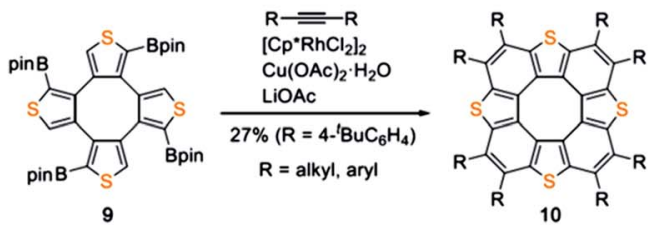

Chart 1 (a) Synthesis of tetraoxa[8]circulene from $\alpha$-naphthoquinone. (b) Synthesis of azatrioxa[8]circulene and diazadioxa[8]circulene from a dihydroxycarbazole precursor. (c) Synthesis of tetraaza[8]circulene from o-phenylene-bridged tetrapyrrole. (d) Synthesis of tetrathia- and tetraselena[8]circulenes from an octabromotetraphenylene precursor. (e) Synthesis of tetrathia[8]circulenes from a tetraboryltetrathienylene precursor ( $\mathrm{DDQ}=2,3$-dichloro-5,6-dicyano- $p$-benzoquinone, chloranil = 2,3,5,6-tetrachloro- $p$-benzoquinone).

dependent optical properties will be discussed in conjunction with further $N$-substituted derivatives.

\section{Results and discussion}

\section{Synthesis}

The synthesis of triaza-quasi-[8]circulene is straightforward; the coupling reaction of indole derivatives with 2,5-bis(2-bromophenyl)pyrrole followed by oxidation under appropriate conditions. $^{12}$ This time, we synthesized a dimethoxysubstituted precursor 11c as a potential cyclization substrate leading to dimethoxy-substituted triaza[7]helicene 13c. However, even under milder oxidative reaction conditions (PIFA at $-78{ }^{\circ} \mathrm{C}$ ), quasi-[8]circulene $12 \mathrm{c}$ was produced in $97 \%$ yield and 13c was not detected (Scheme 1). This result has been ascribed to the higher spin density at the 4-position than at the 3 -position in the cation radical of 11c (see Fig. S5-1, ESI $\dagger$ ). Therefore, intramolecular 4,4'-oxidative coupling in 11c proceeded preferably in spite of the steric repulsion imposed by the two methoxy groups. In contrast, the spin density distribution is reversed in the case of the dichloro-substituted precursor 11d, which preferred oxidative coupling between the central pyrrole and indole 3-position to give triaza[7]helicene 13d in 95\% yield. The structures of 12c and 13d were unambiguously revealed by X-ray diffraction analysis (Fig. 1). Both compounds displayed highly twisted structures, the degree of which can be quantified by mean-plane deviation (MPD) values to be $0.45 \AA$ for $12 \mathrm{c}$ and $0.55 \AA$ for $13 \mathrm{~d}$ (35 atoms). The value of $12 \mathrm{c}$ is distinctly larger than that of $12 \mathrm{a}(0.31 \AA)$ due to the two methoxy groups. Because of the twisted structures, intermolecular $\pi-\pi$ stacking is not favorable. In the crystal lattice, two or three THF molecules are encapsulated and form hydrogen bonds with pyrrolic NH sites.

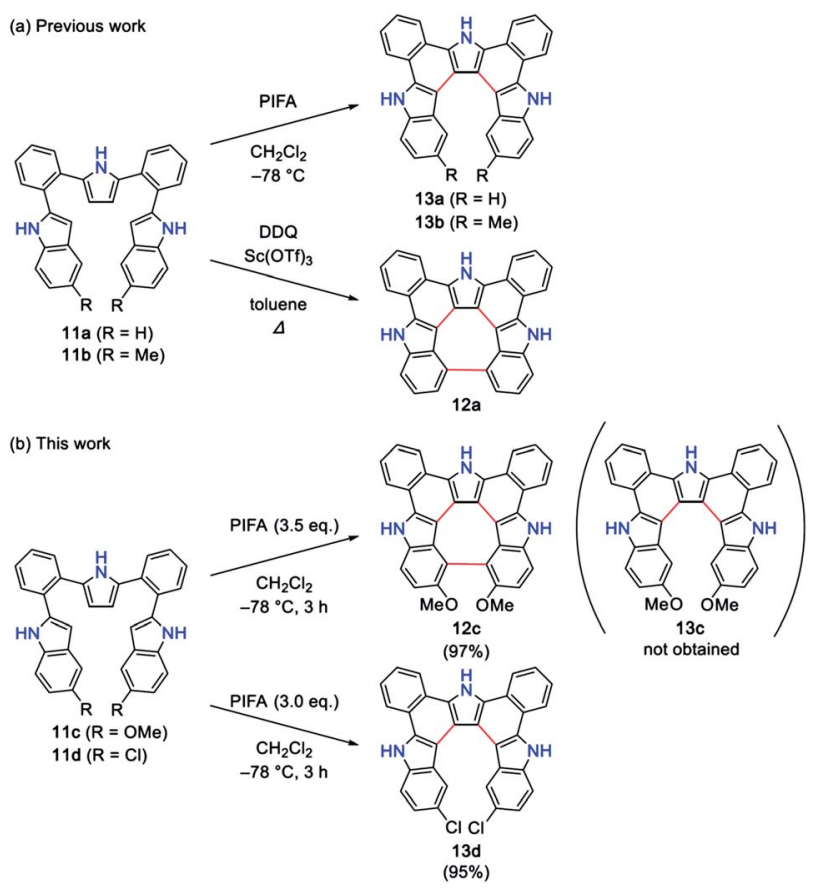

Scheme 1 (a) Selective synthesis of triaza-quasi-[8]circulene 12a and triaza[7]helicenes 13a,b. (b) Unexpected formation of triaza-quasi-[8] circulene 12c under mild conditions, and the formation of triaza[7] helicene 13d under the same conditions (PIFA = bis(trifluoroacetoxy) iodobenzene). 


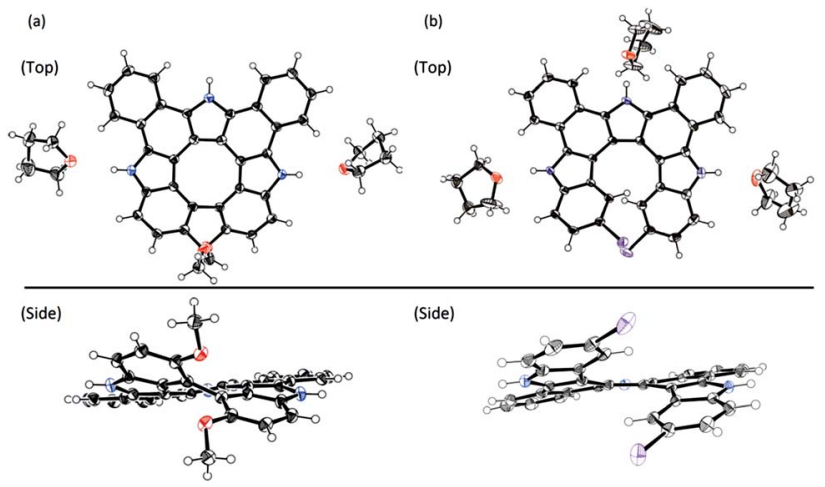

Fig. 1 X-ray crystal structures of (a) $12 c$ and (b) $13 \mathrm{~d}$. The thermal ellipsoids were scaled to $50 \%$ probability level. Solvent molecules were omitted in the side views.

It is well known that biphenylene-2,2'-diol derivatives undergo thermal dehydration reaction to afford the corresponding dibenzofuran derivatives. ${ }^{13}$ We attempted demethylation of $12 \mathrm{c}$ with $\mathrm{BBr}_{3}$ in $\mathrm{CH}_{2} \mathrm{Cl}_{2}$ at room temperature, which gave triazaoxa[8]circulene $\mathbf{1 4}$ as a yellow solid in $73 \%$ yield (Scheme 2). Matrix-assisted-laser-desorption-ionization time-offlight mass spectrometry (MALDI-TOF-MS) revealed the molecular ion peak of 14 at $m / z=457.1218$ (calcd for $\mathrm{C}_{32} \mathrm{H}_{15} \mathrm{~N}_{3} \mathrm{O}=$ $\left.457.1210[\mathrm{M}]^{+}\right)$. The ${ }^{1} \mathrm{H}$ NMR spectrum in DMSO- $d_{6}$ showed two $\mathrm{NH}$ peaks at 12.93 and $12.64 \mathrm{ppm}$ and six peaks at 9.09, 8.82, 7.98, 7.96, 7.83 and $7.77 \mathrm{ppm}$. Even at low temperature, the corresponding diol intermediate was not isolated, presumably because of the fast dehydration reaction in the diol intermediate driven by strain release. It is noteworthy that this is the first example of hetero[8]circulene consisting of three pyrrole units and one furan unit. All the reaction steps are high yielding and the reaction products are easily separable, thus allowing us to obtain 14 in more than $300 \mathrm{mg}$ quantity. In spite of the lack of solubilizing substituents, $\mathbf{1 4}$ is quite soluble in acetone and THF but less soluble in $\mathrm{CH}_{2} \mathrm{Cl}_{2}$. The single crystal structure of 14 is shown in Fig. 2. The molecule is almost planar with a MPD value of $0.014 \AA$ (35 atoms). Three acetone molecules adopt hydrogen bonding with the three NH sites, and the layer of three acetone molecules prevents the planar core molecule from intermolecular $\pi-\pi$ contact. The contribution of the central formal $8 \pi$ cyclooctatetraene moiety is another point to discuss. The constituent eight $\mathrm{C}-\mathrm{C}$ bond lengths are in the range of 1.404(2)-1.431(2) $\AA$ (see Fig. S6-5, ESI $\dagger$ ). The NICS(0) and $\operatorname{NICS}(1)_{\mathrm{zz}}$ values at the center of the eight-membered ring were calculated by the GIAO method to be +7.00 and $+18.05 \mathrm{ppm}$,
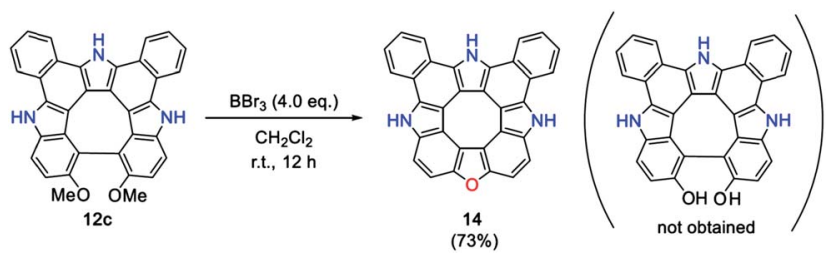

Scheme 2 Synthesis of triazaoxa[8]circulene 14.

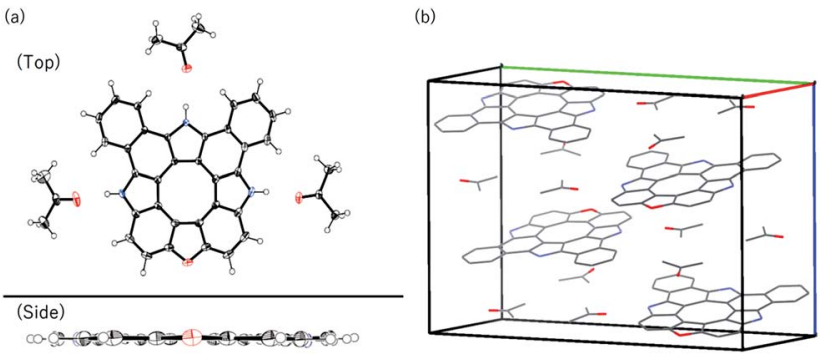

Fig. 2 (a) X-ray crystal structures of 14. The thermal ellipsoids were scaled to $50 \%$ probability level. Solvent molecules in the side view were omitted for clarity. (b) Packing diagram.

respectively (Fig. S5-12 and S5-13, ESI $\dagger$ ). This situation is in analogy to other hetero[8]circulenes. ${ }^{7,8}$ Although it may have decent antiaromatic contributions, we would say that the aromatic contributions of each benzene, pyrrole and furan moiety are predominant as indicated by HOMA and NICS(0) values at the centre points of each aromatic ring (see Fig. S5-14, ESI†).

\section{$N$-substitution reactions}

An advantage of the new synthetic scheme for 14 against other [8]circulene syntheses may be the presence of the intact $\mathrm{NH}$ moieties which can be further decorated. Previously, we reported that sequential $N$-butylation of tetraaza[8]circulene 5 slightly altered its optical properties. ${ }^{14}$ Along with this strategy, $\mathrm{N}$-alkylation reactions were tested for $12 \mathrm{a}, 12 \mathrm{c}$ and 14 . $N$-Butylation was easily achieved for 12a and $\mathbf{1 4}$ by utilizing the reported method (excess NaH, 1-iodobutane in THF) to give tributylated products 12a-Bu and 14-Bu in $43 \%$ and $78 \%$ yields, respectively. ${ }^{\mathbf{1 4}, 15}$ On the other hand, the same reaction of $12 \mathrm{c}$ resulted in a very low yield of $N$-butylated products. It is likely that the highly twisted structure of 12c causes degradation under these conditions. Then, the reaction conditions were screened, and we found that the treatment of $12 \mathrm{c}$ with 200 equivalents of 1 -iodobutane in the presence of potassium tert-butoxide at room temperature for 24 hours afforded 12c-Bu in $46 \%$ yield. All the solid-state structures have been revealed by X-ray diffraction analysis as shown in Scheme 3. The planarity and bond-length alternation do not change so much for 14-Bu, while the degree of non-planarity of 12a-Bu and 12c-Bu increased compared with 12a and 12c.

With these in hand, we next investigated their aggregation behaviours in solution. Basically, all these hetero[8]circulene analogues are quite soluble in THF and the absorption spectra obey the Beer-Lambert law in the UV/vis concentration (ca. $10^{-5}-10^{-6} \mathrm{M}$ ) (see Fig. S7-1 and S7-2, ESI $\dagger$ ). The tri- $N$-butylated products were more soluble in less polar solvents as compared with non-substituted ones. For instance, the solubilities of $\mathbf{1 4}$ and 14-Bu were roughly estimated by a simple filtration experiment to be $0.15 \mathrm{mg} \mathrm{mL}^{-1}$ in $\mathrm{CH}_{2} \mathrm{Cl}_{2}$ for 14 and $26 \mathrm{mg} \mathrm{mL}^{-1}$ in $\mathrm{CH}_{2} \mathrm{Cl}_{2}$ for 14-Bu at room temperature, while those in acetone were comparable $\left(4.6 \mathrm{mg} \mathrm{mL}^{-1}\right.$ for 14 and $5.1 \mathrm{mg} \mathrm{mL}^{-1}$ for 14Bu) (see Table S9-1, ESI $\dagger$ ). In addition, 12a-Bu, 12c-Bu and 14-Bu are even soluble in $n$-hexane. On the other hand, 12a, 12c and 14 


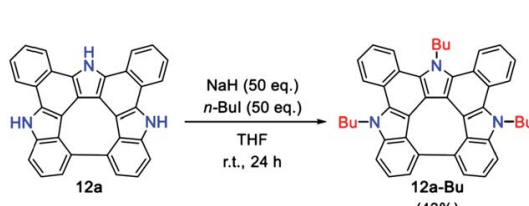
(43\%)

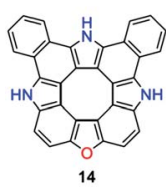

$\mathrm{NaH}(50$ eq.) $\underset{\mathrm{THF}}{\mathrm{n} \text {-Bul (50 eq.) }}$
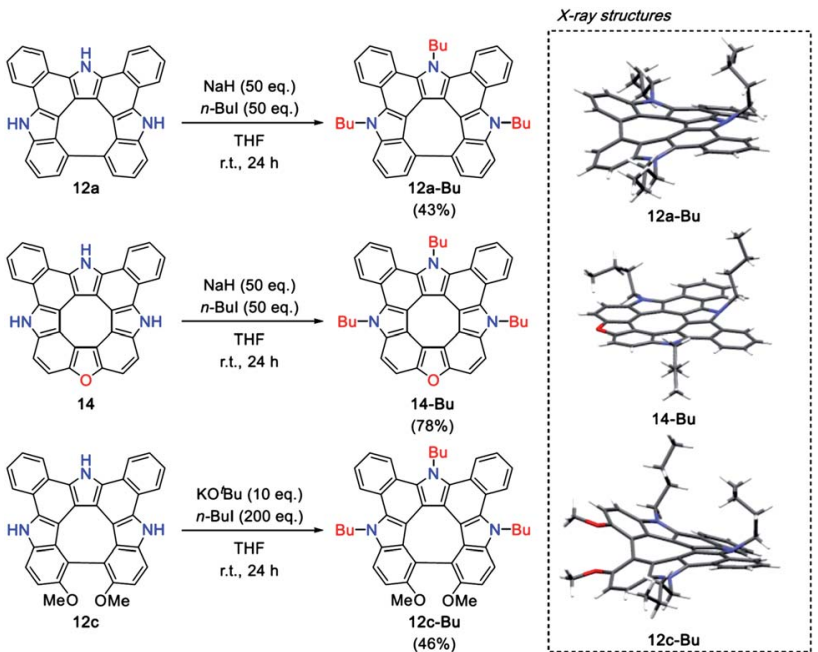

Scheme $3 \quad N$-substitution reactions and the X-ray crystal structures of 12a-Bu, 12c-Bu and 14-Bu. Solvent molecules were omitted for clarity.

bearing intact $\mathrm{NH}$ sites are especially soluble in hydrogen-bond accepting solvents such as THF, acetone and DMSO. They are also soluble in a mixed solvent, up to $10 \%$ THF in $n$-hexane, without the observation of aggregation-induced fluorescence quenching (Fig. S7-9†). In the solid state, the emission spectra were completely quenched.

Nanographenes are, in many cases, only soluble in halogenated solvents, and the low solubility often hampers further functionalization and applications. ${ }^{16}$ The high solubility can be a unique feature of hetero[8]circulenes possessing intact $\mathrm{NH}$ sites, and is useful for solution-processed electronics applications and is potentially applicable for biochemistry. ${ }^{17}$

\section{Optical properties}

Hetero[8]circulenes are highly luminescent molecules upon photoirradiation because of their rigid structures that prevent thermal energy loss due to structural change in the excited state. In fact, tetraaza[8]circulene $\mathbf{5}$ showed a very small Stokes shift

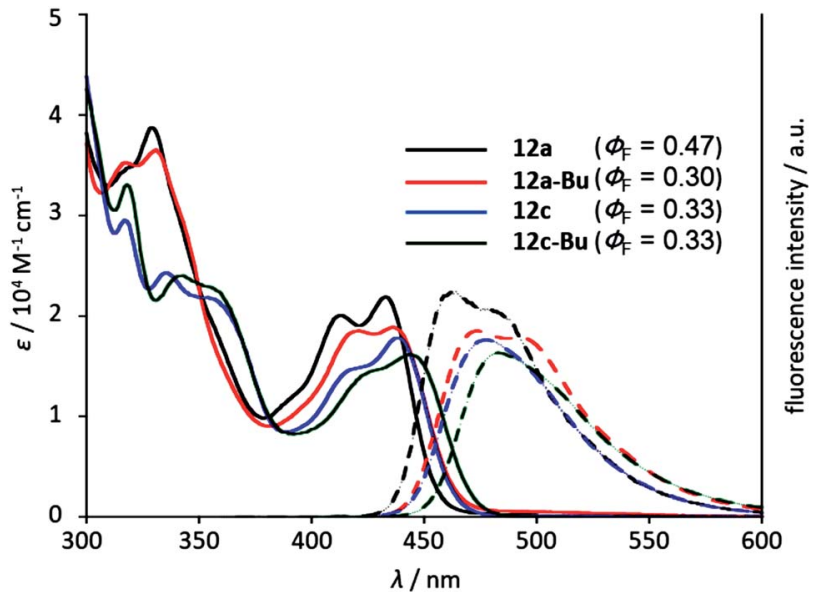

Fig. $3 U$ UV/vis absorption and emission spectra of $12 \mathrm{a}, 12 \mathrm{a}-\mathrm{Bu}, 12 \mathrm{c}$ and 12c-Bu in THF.

(ca. $180 \mathrm{~cm}^{-1}$ ) in THF with a high fluorescence quantum yield $\left(\Phi_{\mathrm{F}}=0.59\right)$. The absorption and emission spectra of quasi-aza [8]circulene 12a are red-shifted with a relatively larger Stokes shift $\left(1450 \mathrm{~cm}^{-1}\right)$ probably due to their non-planar conformations. The absorption spectrum of $12 \mathrm{c}$ is further shifted up to $474 \mathrm{~nm}$ compared with that of $\mathbf{1 2 a}(433 \mathrm{~nm})$ (Fig. 3 and Table 1$)$. DFT calculations revealed that the larger non-planarity of 12c raised its HOMO energy level, giving rise to the decreased HOMO-LUMO gap (see Fig. S5-8, ESI†). Instead, the emission quantum yield was decreased to $\Phi_{\mathrm{F}}=0.33$. Upon $N$-butylation, the absorption and emission spectra were red-shifted. While 12a-Bu and 14-Bu showed decreased $\Phi_{\mathrm{F}}$ values from nonbutylated ones, 12c and 12c-Bu displayed the same $\Phi_{\mathrm{F}}$ values in THF.

Triazaoxa[8]circulene $\mathbf{1 4}$ has a rigid and planar structure like 5, but exhibited red-shifted absorption and emission bands (Fig. 4). The decrease of the molar extinction coefficient is ascribed to its lower symmetry, while the red-shift may be due to the lack of two benzo-fused segments. Azatrioxa[8] circulene 2

Table 1 Summary of the properties

\begin{tabular}{|c|c|c|c|c|c|c|c|c|}
\hline Compound & Solvent & $\lambda_{\mathrm{abs}}(\mathrm{nm})$ & $\lambda_{\text {flu }}(\mathrm{nm})$ & Stokes shift $\left(\mathrm{cm}^{-1}\right)$ & $\Phi_{\mathrm{F}}$ & $\tau_{\mathrm{F}}(\mathrm{ns})$ & $k_{\mathrm{r}}\left(\times 10^{8} \mathrm{~s}^{-1}\right)$ & $k_{\mathrm{nr}}\left(\times 10^{8} \mathrm{~s}^{-1}\right)$ \\
\hline $5^{a}$ & THF & 413 & 416 & 180 & 0.59 & 3.8 & 1.6 & 1.1 \\
\hline $12 a$ & $\mathrm{THF}$ & 433 & 462 & 1450 & 0.47 & 5.6 & 0.83 & 0.94 \\
\hline $12 a$ & DMSO & 436 & 490 & 2530 & 0.58 & 8.2 & 0.71 & 0.51 \\
\hline 12a-Bu & THF & 436 & 473 & 1790 & 0.30 & 5.1 & 0.59 & 1.4 \\
\hline 12a-Bu & DMSO & 435 & 496 & 2830 & 0.42 & 6.7 & 0.62 & 0.87 \\
\hline $12 \mathrm{c}$ & THF & 426 & 476 & 1680 & 0.33 & 3.6 & 0.92 & 1.8 \\
\hline $12 \mathrm{c}$ & DMSO & 444 & 485 & 1900 & 0.49 & 4.6 & 1.1 & 1.1 \\
\hline 12c-Bu & THF & 443 & 491 & 1870 & 0.33 & 4.0 & 0.82 & 1.7 \\
\hline $12 c-B u$ & DMSO & 447 & 494 & 2130 & 0.42 & 5.0 & 0.84 & 1.2 \\
\hline 14 & THF & 426 & 437 & 590 & 0.52 & 4.5 & 1.2 & 1.1 \\
\hline 14 & DMSO & 429 & 449 & 1040 & 0.72 & 5.7 & 1.3 & 0.50 \\
\hline 14-Bu & THF & 440 & 451 & 550 & 0.40 & 4.1 & 0.97 & 1.5 \\
\hline 14-Bu & DMSO & 442 & 460 & 890 & 0.70 & 4.8 & 1.5 & 0.62 \\
\hline
\end{tabular}

${ }^{a}$ See ref. 8 a. 


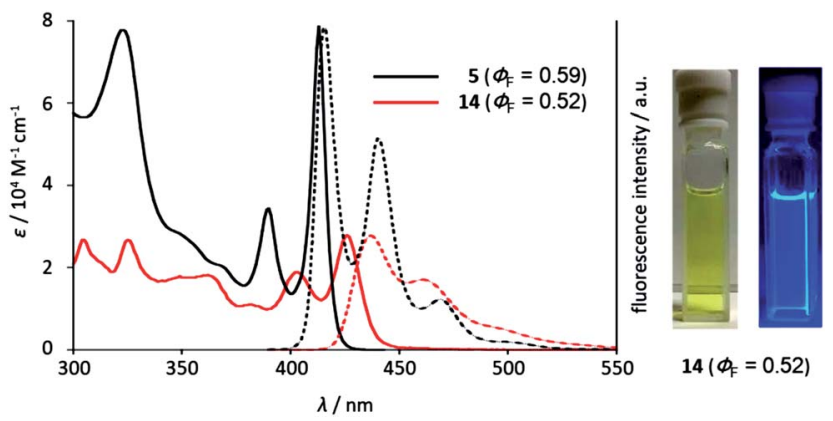

Fig. 4 UV/vis absorption and emission spectra of 5 and 14 in THF. The right figures show the photos (under room light and under UV light).

also showed a similar shift compared with a non-benzo-fused analogue. ${ }^{7 a}$ This tendency is consistent with theoretical calculations (see Fig. S5-10, ESI†). ${ }^{18}$

As described above, 14-Bu is quite soluble both in polar and non-polar solvents without any aggregation effects. Thus, the absorption and emission spectra were recorded in various solvents as shown in Fig. 5 . The absorption spectra are almost unchanged in various solvents with clear vibronic structures, while the emission spectra are slightly but gradually red-shifted as the polarity of the solvent increases. Interestingly, the emission is largely enhanced up to $\Phi_{\mathrm{F}}=0.70$ in DMSO. This tendency is also observed for $\mathbf{1 4}$ (Table 1 and Fig. S7-5†). The fluorescence lifetimes $\left(\tau_{\mathrm{F}}\right)$ were measured using the timecorrelated single photon counting (TCSPC) technique. The longest lifetimes were observed in DMSO in all cases, but mostly the $\tau_{\mathrm{F}}$ values are in the range of 3.0-7.0 ns. From these optical parameters, the radiative rate constant $\left(k_{\mathrm{r}}\right)$ and non-radiative rate constant $\left(k_{\mathrm{nr}}\right)$ were estimated. In $\mathbf{1 4}$ and 14-Bu, larger $k_{\mathrm{r}}$ and

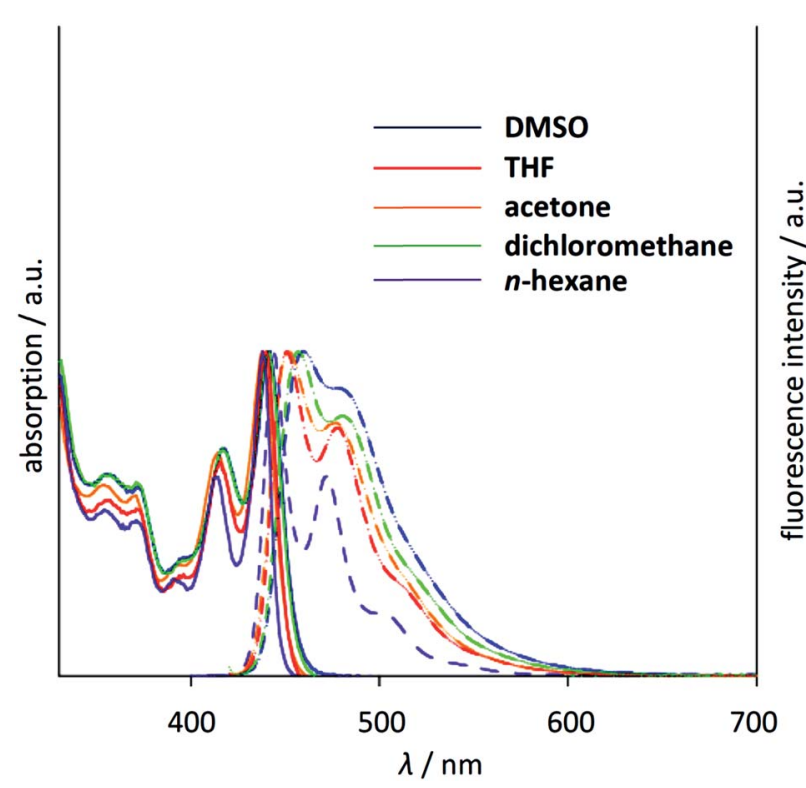

Fig. 5 Normalized UV/vis absorption (solid lines) and emission (dashed lines) spectra of 14-Bu in $n$-hexane (purple), THF (red), $\mathrm{CH}_{2} \mathrm{Cl}_{2}$ (green), acetone (orange) and DMSO (blue). smaller $k_{\mathrm{nr}}$ both contributed to higher emission in DMSO. ${ }^{19}$ For others, the larger $\Phi_{\mathrm{F}}$ values in polar solvents were mainly attributed to smaller $k_{\mathrm{nr}}$ values. Thus, deactivation processes in the excited state can be somehow suppressed in polar solvents.

\section{Chiral separation}

The highly twisted structure of quasi-aza[8]circulene 12c prompted us to examine its enantiomeric separation. Although the racemization activation barrier of 12a was computed to be about $6.0 \mathrm{kcal} \mathrm{mol}^{-1},{ }^{12}$ that of $12 \mathrm{c}$ was estimated to be more than $40 \mathrm{kcal} \mathrm{mol}^{-1}$ (see Fig. S10-2, ESI $\dagger$ ). Through screening of the chiral stationary phase and eluents, we found that $12 \mathrm{c}-\mathrm{Bu}$ was successfully separated by HPLC equipped with a CHIRALPAK IA-3 ( $\varphi=4.6 \mathrm{~mm}$, Daicel Co.) with $\mathrm{CH}_{2} \mathrm{Cl}_{2}$ as an eluent. The enantiomers were completely separated and the circular dichroism (CD) spectra showed a mirror-image pattern (Fig. 6). The first fraction which showed a negative Cotton effect at around $450 \mathrm{~nm}$ was assigned as the $(M)$ twisted form by comparing with the calculated CD spectrum (see Fig. S10-3, ESI $\dagger$ ). This CD spectral feature resembles that of quasi-[7]circulene derivatives, ${ }^{20}$ but is reversed when compared with azahelicene derivatives. ${ }^{12,21}$ The enantiomers were quite stable and no racemization took place under heating in toluene. Since 12cBu is soluble in various solvents, this may be useful in chiral recognition in suitable media. While Wong et al. reported the
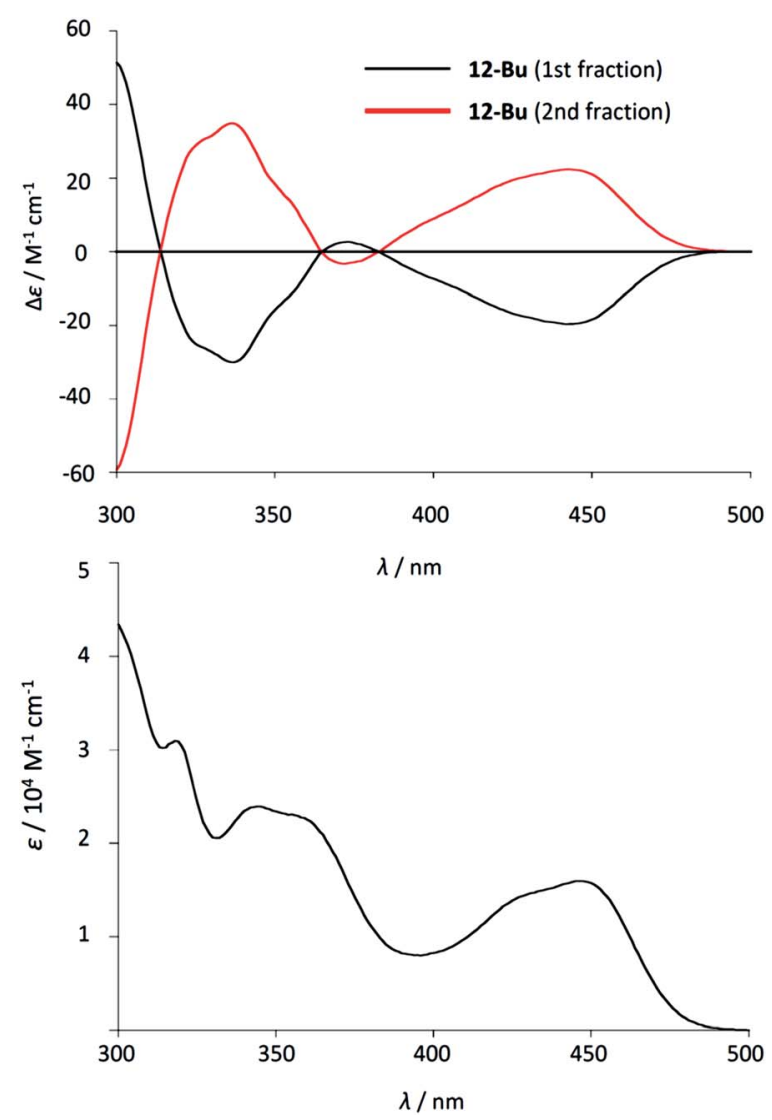

Fig. 6 (Top) CD and (bottom) UV/vis absorption spectra of the first fraction (black) and the second fraction (red) of $12 \mathrm{c}-\mathrm{Bu}$ in $\mathrm{CH}_{2} \mathrm{Cl}_{2}$. 
chiral properties of tetraphenylene-based molecules, ${ }^{22}$ enantiomeric separation of polycondensed nanographene-like molecules other than helicenes is quite rare. ${ }^{23}$

\section{Conclusions}

In summary, non-planar quasi-aza[8]circulene derivatives and planar triazaoxa[8]circulene were prepared in good yields via a facile synthetic protocol. These hetero[8]circulenes are highly soluble in organic solvents without solubilizing substituents due to the hydrogen bonding interaction between the outerpointing $\mathrm{NH}$ site and hydrogen-bond accepting solvent. Furthermore, $N$-alkylation reactions facilitated tuning of the solubility and optical properties. Taking advantage of the nonaggregation behaviours in various solvents, we studied the solvent effects on the absorption and emission spectra as well as emission lifetime. As an important finding, the fluorescence quantum yields were enhanced in DMSO mostly due to the suppression of non-radiative decay from the excited state. Among them, triazaoxa[8]circulenes 14 and 14-Bu showed high fluorescence quantum yields of 0.72 and 0.70 in DMSO, respectively. Enantiomeric separation of 12c-Bu was also successfully achieved using the chiral HPLC technique as the first chiral quasi-[8]circulene derivative. Further exploration of the synthesis and characterization of novel hetero[8]circulenes is in progress in our laboratory.

\section{Conflicts of interest}

There are no conflicts to declare.

\section{Acknowledgements}

The work was supported by JSPS KAKENHI Grant Numbers (JP18K14199, JP16H00909 and JP18H03910). K. K. acknowledges a JSPS Fellowship for Young Scientists. We appreciate Prof. Tsuyoshi Kawai, Dr Mihoko Yamada and Mr Yuto Yoshida (NAIST) for circular dichroism measurements.

\section{Notes and references}

1 (a) Carbon-Rich Compounds, ed. M. M. Haley and R. R. Tykwinski, Wiley-VCH, Weinheim, 2006; (b) Functional Organic Materials, ed. T. J. J. Müller and U. H. F. Bunz, Wiley-VCH, Weinheim, 2007; (c) Polycyclic Arenes and Heteroarenes, ed. Q. Miao, Wiley-VCH, New York, 2015.

2 (a) A. Narita, X.-Y. Wang, X. Feng and K. Müllen, Chem. Soc. Rev., 2015, 44, 6616; (b) M. Stępień, E. Gońka, M. yła and N. Sprutta, Chem. Rev., 2017, 117, 3479; (c) M. A. Majewski and M. Stępień, Angew. Chem., Int. Ed., 2019, 58, 86; (d) M. Grzybowski, B. Sadowski, H. Butenschön and D. T. Gryko, Angew. Chem., Int. Ed., 2019, 58, DOI: 10.1002/ anie.201904934.

3 (a) M. Stępień, Synlett, 2013, 24, 1316; (b) C.-N. Feng, Y.-C. Hsieh and Y.-T. Wu, Chem. Rec., 2015, 15, 266; (c) T. Hensel, N. N. Andersen, M. Plesner and M. Pittelkow, Synlett, 2016, 27, 498.
4 (a) C.-N. Feng, M.-Y. Kuo and Y.-T. Wu, Angew. Chem., Int. Ed., 2013, 52, 7791; (b) Y. Sakamoto and T. Suzuki, J. Am. Chem. Soc., 2013, 135, 14074; (c) R. W. Miller, A. K. Duncan, S. T. Schneebeli, D. L. Gray and A. C. Whalley, Chem.-Eur. J., 2014, 20, 3705; (d) C.-N. Feng, W.-C. Hsu, J.-Y. Li, M.-Y. Kuo and Y.-T. Wu, Chem.-Eur. J., 2016, 22, 9198.

5 H. Erdtman and H.-E. Högberg, The first synthetic attempt can be further traced back to 1881 when Knapp and Schultz reported that $\alpha$-naphthoquinone was reacted with concentrated hydrochloric acid to give insoluble material. Erdtman also synthesized the same material in 1933. However, the product had been mis-assigned and it was finally proved to be 1 in 1968, Chem. Commun., 1968, 773.

6 (a) H. Erdtman and H.-E. Högberg, Tetrahedron Lett., 1970, 11, 3389; (b) J.-E. Berg, H. Erdtman, H.-E. Högberg, B. Karlsson, A.-M. Pilotti and A.-C. Söderholm, Tetrahedron Lett., 1977, 18, 1831; (c) H. Erdtman and H.-E. Högberg, Tetrahedron, 1979, 35, 535; (d) J. Eskildsen, T. Reenberg and J. B. Christensen, Eur. J. Org. Chem., 2000, 1637; (e) R. Rathore and S. H. Abdelwahed, Tetrahedron Lett., 2004, 45, 5267; $(f)$ C. B. Nielsen, T. Brock-Nannestad, T. K. Reenberg, P. Hammershøj, J. B. Christensen, J. W. Stouwdam and M. Pittelkow, Chem.-Eur. J., 2010, 16, 13030; (g) T. Brock-Nannestad, C. B. Nielsen, M. SchauMagnussen, P. Hammershøj, T. K. Reenberg, A. B. Petersen, D. Trpcevski and M. Pittelkow, Eur. J. Org. Chem., 2011, 6320; (h) S. L. Mejlsøe and J. B. Christensen, J. Heterocycl. Chem., 2014, 51, 1051.

7 (a) C. B. Nielsen, T. Brock-Nannestad, P. Hammershøj, T. K. Reenberg, M. Schau-Magnussen, D. Trpcevski, T. Hensel, R. Salcedo, G. V. Baryshnikov, B. F. Minaev and M. Pittelkow, Chem.-Eur. J., 2013, 19, 3898; (b) T. Hensel, D. Trpcevski, C. Lind, R. Grosjean, P. Hammershøj, C. B. Nielsen, T. Brock-Nannestad, B. E. Nielsen, M. SchauMagnussen, B. Minaev, G. V. Baryshnikov and M. Pittelkow, Chem.-Eur. J., 2013, 19, 17097; (c) M. Plesner, T. Hensel, B. E. Nielsen, F. S. Kamounah, T. BrockNannestad, C. B. Nielsen, C. G. Tortzen, O. Hammerich and M. Pittelkow, Org. Biomol. Chem., 2015, 13, 5937.

8 (a) F. Chen, Y. S. Hong, S. Shimizu, D. Kim, T. Tanaka and A. Osuka, Angew. Chem., Int. Ed., 2015, 54, 10639; (b) Y. Nagata, S. Kato, Y. Miyake and H. Shinokubo, Org. Lett., 2017, 19, 2718.

9 (a) X. Xiong, C.-L. Deng, B. F. Minaev, G. V. Baryshnikov, X.-S. Peng and H. N. C. Wong, Chem.-Asian J., 2015, 10, 969; (b) X. Xiong, C.-L. Deng, Z. Li, X.-S. Peng and H. N. C. Wong, Org. Chem. Front., 2017, 4, 682.

10 (a) S. Kato, Y. Serizawa, D. Sakamaki, S. Seki, Y. Miyake and H. Shinokubo, Chem. Commun., 2015, 51, 16944; (b) S. Kato, S. Akahori, Y. Serizawa, X. Lin, M. Yamauchi, S. Yagai, T. Sakurai, W. Matsuda, S. Seki, H. Shinokubo and Y. Miyake, J. Org. Chem., 2019, DOI: 10.1021/acs.joc.9b01655. 11 A. Rajca, M. Miyasaka, S. Xiao, P. J. Boratyński, M. Pink and S. Rajca, Another expression of 13a is dibenzohepta[8] circulene as previously reported, ${ }^{12,19}$ but here we use the 
term, quasi-[8]circulene to emphasize the resemblance as referred to the Rajca's report, J. Org. Chem., 2009, 74, 9105.

12 F. Chen, T. Tanaka, T. Mori and A. Osuka, Chem.-Eur. J., 2018, 24, 7489.

13 (a) K. Nakanishi, D. Fukatsu, K. Takaishi, T. Tsuji, K. Uenaka, K. Kuramochi, T. Kawabata and K. Tsubaki, J. Am. Chem. Soc., 2014, 136, 7101; (b) M. S. Sundar and A. V. Bedekar, Org. Lett., 2015, 17, 5808; (c) C. Mitsui, M. Yamagishi, R. Shikata, H. Ishii, T. Matsushita, K. Nakahara, M. Yano, H. Sato, A. Yamano, J. Takeya and T. Okamoto, Bull. Chem. Soc. Jpn., 2017, 90, 931; (d) T. Okamoto, H. Dosei, M. Mitani, Y. Murata, H. Ishii, K.-i. Nakamura, M. Yamagishi, M. Yano and J. Takeya, Asian J. Org. Chem., 2018, 7, 2309.

14 (a) F. Chen, Y. S. Hong, D. Kim, T. Tanaka and A. Osuka, ChemPlusChem, 2017, 82, 1048; (b) G. V. Baryshnikov, R. R. Valiev, B. F. Minaev and H. Ågren, New J. Chem., 2017, 41, 7621.

15 (a) F. Chen, T. Tanaka, Y. S. Hong, W. Kim, D. Kim and A. Osuka, Chem.-Eur. J., 2016, 22, 10597; (b) F. Chen, T. Tanaka and A. Osuka, Chem. Commun., 2017, 53, 2705.

16 J. C. Fetzer, Large Polycyclic Aromatic Molecules - Chemistry and Analysis, Wiley Interscience, New York, 2000.

17 Water-soluble nanographenes and their biological applications: (a) H. A. Lin, Y. Sato, Y. Segawa, T. Nishihara, N. Sugimoto, L. T. Scott, T. Higashiyama and K. Itami, Angew. Chem., Int. Ed., 2018, 57, 2874; (b) C. Liu, S. Zhang,
J. Li, J. Wei, K. Müllen and M. A. Yin, Angew. Chem., Int. Ed., 2019, 58, 1638.

18 N. N. Karaush, G. V. Baryshnikov, V. A. Minaeva, H. Ågren and B. F. Minaev, Mol. Phys., 2017, 115, 2218.

19 From the Strickler-Berg relationship, larger $k_{\mathrm{r}}$ values can be attributed to a larger absorption coefficient at the lowestenergy band. Indeed, 12 and 12-Bu displayed absorption bands at $429 \mathrm{~nm}\left(\varepsilon=38000 \mathrm{M}^{-1} \mathrm{~cm}^{-1}\right)$ and $441 \mathrm{~nm}(\varepsilon=$ $39000 \mathrm{M}^{-1} \mathrm{~cm}^{-1}$ ) in DMSO, which are larger than those in THF (Fig. S7-11, ESI $\dagger$ ).

20 K. Yamamoto, T. Harada, Y. Okamoto, H. Chikamatsu, M. Nakazaki, Y. Kai, T. Nakao, M. Tanaka, S. Harada and N. Kasai, J. Am. Chem. Soc., 1988, 110, 3579.

21 I. Pischel, S. Grimme, S. Kotila, M. Nieger and F. Vögtle, Tetrahedron: Asymmetry, 1996, 7, 109.

22 (a) J.-W. Han, X. Li and H. N. C. Wong, Chem. Rec., 2015, 15, 107; (b) P. Rashidi-Ranjbar, Y. M. Man, J. Sandstroem and H. N. C. Wong, J. Org. Chem., 1989, 54, 4888; (c) H.-Y. Peng, C.-K. Lam, T. C. W. Mak, Z. Cai, W.-T. Ma, Y.-X. Li and H. N. C. Wong, J. Am. Chem. Soc., 2005, 127, 9603.

23 Selected reviews of chiral nanographenes: (a) E. E. Maroto, M. Izquierdo, S. Reboredo, J. Marco-Martínez, S. Filippone and N. Martin, Acc. Chem. Res., 2014, 47, 2660; (b) I. R. Márquez, S. Castro-Fernández, A. Millán and A. G. Campaña, Chem. Commun., 2018, 54, 6705; (c) M. Rickhaus, M. Mayor and M. Jurícek, Chem. Soc. Rev., 2017, 46, 1643. 